\title{
Isolating Clusters of Light Elements in Molecular Sieves with Atom Probe Tomography
}

Joel E. Schmidt, ${ }^{\dagger}$ Linqing Peng, ${ }^{\text {II }}$ Alessandra Lucini Paioni, ${ }^{\S}$ Helena Leona Ehren, ${ }^{\S}$ Wei Guo, ${ }^{\ddagger \odot}$ Baishakhi Mazumder, ${ }^{\ddagger}, \nabla$ D. A. Matthijs de Winter,,$\| \#$ Özgün Attila, ${ }^{\dagger}$ Donglong Fu, ${ }^{\dagger}$ Abhishek Dutta Chowdhury, ${ }^{\dagger} \odot$ Klaartje Houben ${ }^{\S, \perp}$ Marc Baldus, ${ }^{\S}$ Jonathan D. Poplawsky, ${ }^{*,+}$ and Bert M. Weckhuysen $* \dagger$

${ }^{\dagger}$ Debye Institute for Nanomaterials Science, Utrecht University, Universiteitsweg 99, 3584 CG Utrecht, The Netherlands

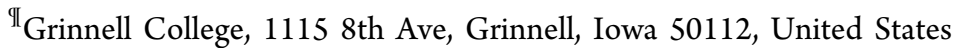

${ }^{\S}$ NMR Spectroscopy, Bijvoet Center for Biomolecular Research, Utrecht University, Padualaan 8, $3584 \mathrm{CH}$ Utrecht, The Netherlands

${ }^{\ddagger}$ Center for Nanophase Materials Sciences, Oak Ridge National Laboratory, Oak Ridge, Tennessee 37831, United States

"Structural Geology \& EM, Utrecht University, Postbus 80.021, 3508 TA Utrecht, The Netherlands

Supporting Information

ABSTRACT: Understanding the 3-D distribution and nature of active sites in heterogeneous catalysts is critical to developing structure-function relationships. However, this is difficult to achieve in microporous materials as there is little relative $\mathrm{z}$ contrast between active and inactive framework elements (e.g., $\mathrm{Al}$, $\mathrm{O}, \mathrm{P}$, and $\mathrm{Si}$ ), making them difficult to differentiate with electron microscopies. We have applied atom probe tomography (APT), currently the only nanometer-scale $3-\mathrm{D}$ microscopy to offer routine light element contrast, to the methanol-to-hydrocarbons (MTH) catalyst SAPO-34, with $\mathrm{Si}$ as the active site, which may be present in the framework as either isolated Si species or clusters (islands) of $\mathrm{Si}$ atoms. ${ }^{29} \mathrm{Si}$ solid-state NMR data on isotopically enriched and natural abundance materials are consistent with the presence of $\mathrm{Si}$ islands, and the APT results have been complemented with simulations to show the smallest detectable cluster size as a function of instrument spatial resolution and detector efficiency. We have identified significant $\mathrm{Si}-\mathrm{Si}$ affinity in the materials, as well as clustering of coke deposited by the MTH reaction $\left({ }^{13} \mathrm{CH}_{3} \mathrm{OH}\right.$ used) and an affinity between Brønsted acid sites and coke. A comparison with simulations shows that the ultimate spatial resolution that can be attained by APT applied to molecular sieves is $0.5-1 \mathrm{~nm}$. Finally, the observed ${ }^{13} \mathrm{C}$ clusters are consistent with hydrocarbon pool mechanism intermediates that are preferentially located in regions of increased Brønsted acidity.

\section{INTRODUCTION}

Catalysts are ubiquitous in our everyday lives with ever expanding applications as an integral part of increasingly sustainable technologies to more efficiently and cleanly utilize limited resources. ${ }^{1,2}$ Heterogeneous catalysts are applied industrially in enormous quantities, and understanding their active site, which is commonly a metal (e.g., $\mathrm{Pt}, \mathrm{Pd}, \mathrm{Cu}, \mathrm{Ni}$, and $\mathrm{Fe}$ ), is of utmost importance for rational improvements. ${ }^{2,3}$ In microporous materials, it is difficult to study the active site using electron microscopies as none of the framework elements (e.g., $\mathrm{Al}, \mathrm{O}, \mathrm{P}, \mathrm{Si}$ ) offer significant relative $\mathrm{z}$-contrast, and these materials are also susceptible to beam damage. ${ }^{4}$ SAPO-34 (CHA framework, 3-D system of 8-membered rings and larger internal cages, Figure 1) is a microporous material that has been applied commercially since 2010 in the methanol-tohydrocarbons (MTH) process. ${ }^{5,6}$ The incorporation of $\mathrm{Si}^{4+}$

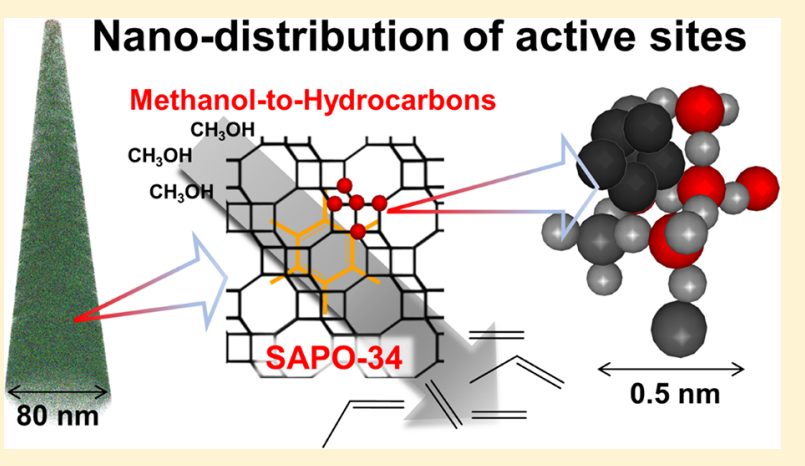

into its framework is a complex process governed by bonding rules as well as crystal structure (section S2), and Si can only exist as isolated species, $\mathrm{Si}(\mathrm{OAl})_{4}$ coordination, or in islands of discrete sizes (Figure 1). ${ }^{7}$ This is commercially vital to control as it dictates catalyst performance, and the bulk Si speciation is typically characterized using ${ }^{29} \mathrm{Si}$ magic angle spinning (MAS) solid-state nuclear magnetic resonance (ssNMR) spectroscopy, which provides a powerful method to sensitively and quantitatively probe $\mathrm{Si}$ speciation. ${ }^{5,8-18}$ After surveying all remaining techniques, the only possibility to image $\mathrm{Si}$ islands is atom probe tomography (APT), which is a 3-D microscopy technique that produces element-specific reconstructions with

Received: April 28, 2018

Published: July 13, 2018 

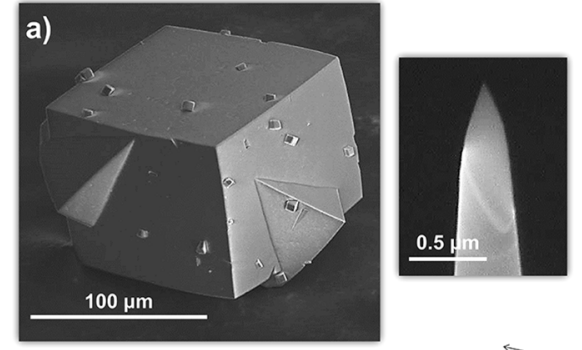

Pulsed laser heating

d)

d) Local electrode

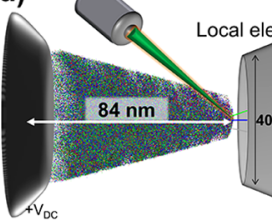

$\uparrow$

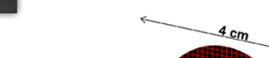

b)

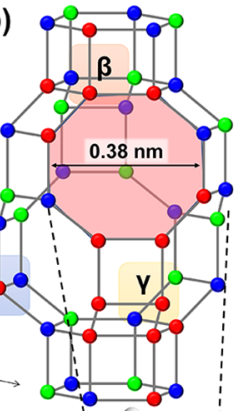

c)

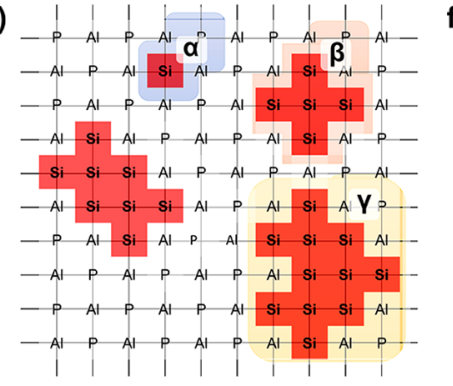

f)

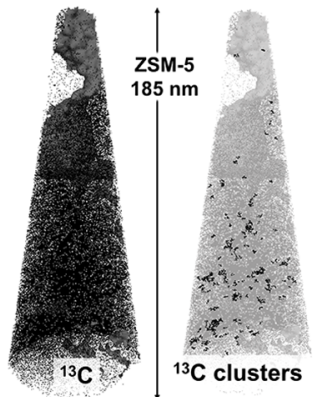

e)
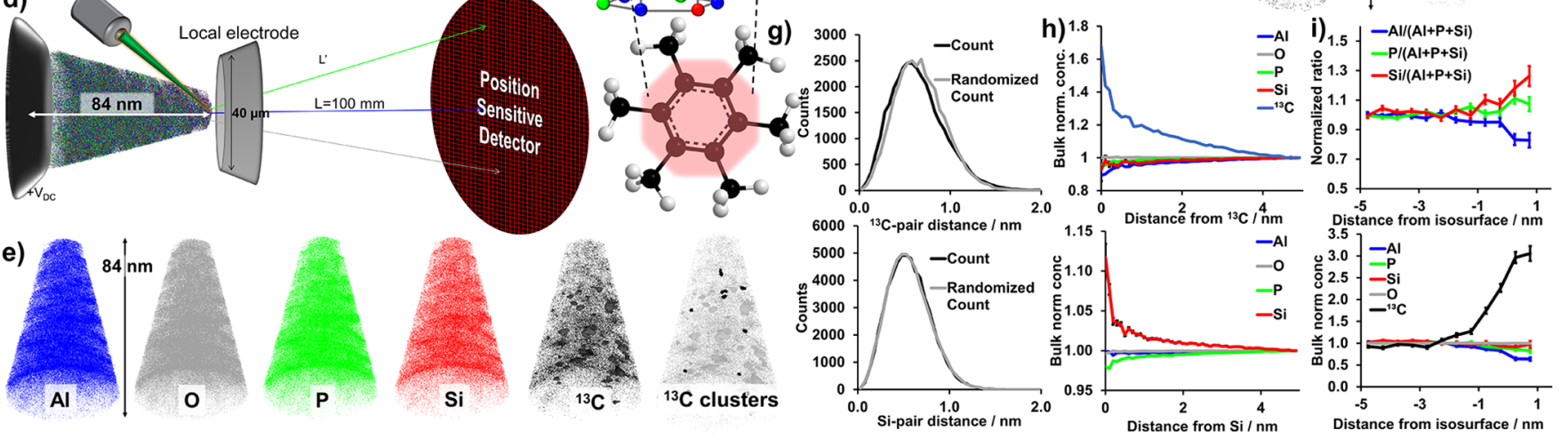

Figure 1. (a) Scanning electron microscope images of SAPO-34 and a needle removed by focused ion beam (FIB) milling prior to the atom probe tomography (APT) experiment. (b) CHA cage of SAPO-34 with an 8-membered ring pore highlighted in yellow, and element colors as shown in (e), with a potential occluded organic highlighted, and different Si environments shown in (c), which is a 2-D schematic of possible Si substitutions into an aluminophosphate framework with $\mathrm{Si}$ island sizes consistent with those found in the CHA crystal structure, which are indicated with $\alpha$, $\beta$, and $\gamma$, corresponding to (b). (d) Schematic of an APT instrument with representative sizes indicated. (e) Reconstruction of a methanol-tohydrocarbons (MTH) reacted SAPO-34 catalyst needle (20), separated by element. In the ${ }^{13} \mathrm{C}$ needle, $7 \%{ }^{13} \mathrm{C}$ isosurfaces are shown, and clusters are highlighted in the adjacent needle (details in section S16). Maximum dimensions of $84 \times 63 \times 62 \mathrm{~nm}^{3}$. (f) Coking from MTH reaction observed in zeolite ZSM-5 (MFI framework) with a $1 \%{ }^{13} \mathrm{C}$ isosurface (needle 3 from ref 19 ) as well as ${ }^{13} \mathrm{C}$ clusters. Maximum needle dimensions of $185 \times 68 \times 66 \mathrm{~nm}^{3}$. (g) Nearest neighbor distribution (NND) for ${ }^{13} \mathrm{C}$ (top) and Si (bottom) in needle 20 . (h) Radial distribution function for ${ }^{13} \mathrm{C}$ in needle 20 and for Si for the combined data of needles $17-22$. (i) Proximity histogram across the $7 \%{ }^{13} \mathrm{C}$ isosurfaces shown in (e) with an increase in carbon content in the coke-rich regions, as well as an increase in the Si content (error bars are discussed in section S8).

nanometer-scale resolution, and has been applied to microporous materials in a few previous studies. ${ }^{1}$

Herein, we have studied seven distinct SAPO-34 samples (Table 1), two of which are prepared with ${ }^{29} \mathrm{Si}$ isotopically

\section{Table 1. Description of Samples and Needles}

\begin{tabular}{|c|c|c|}
\hline $\begin{array}{l}\text { sample } \\
\text { number }\end{array}$ & description & $\begin{array}{l}\text { APT needle } \\
\text { numbers }\end{array}$ \\
\hline 1 & high-Si SAPO-34, calcined & \\
\hline 2 & low-Si SAPO-34, calcined & \\
\hline 3 & $\begin{array}{l}{ }^{29} \mathrm{Si} \text { enriched, high-Si SAPO-34, } \\
\text { calcined }\end{array}$ & $1-3$ \\
\hline 4 & $\begin{array}{l}{ }^{29} \text { Si enriched, low-Si SAPO-34, } \\
\text { calcined }\end{array}$ & 4,5 \\
\hline 5 & large crystals SAPO-34, fresh & $6-11$ \\
\hline 6 & large crystals SAPO-34, calcined & $12-16$ \\
\hline 7 & large crystals SAPO-34, MTH reacted & $17-22$ \\
\hline
\end{tabular}

enriched $\mathrm{Si}$ to enhance the ${ }^{29} \mathrm{Si}$ MAS ssNMR signal and simplify Si identification in the APT data analysis. The SAPO34 phase was confirmed using powder X-ray diffraction (Figures S1-S4). One-dimensional ${ }^{29} \mathrm{Si}$ ssNMR spectra suggested that all materials contained Si islands (section S6, Figures S5-S9), surprisingly even those with a low Si content. $^{26}$ Samples 3-7 were studied using APT as samples 1 and 2 were for NMR comparisons. APT data collection and interpretation was challenging for SAPO-34 due to the presence of organics and larger than ideal mass spectral thermal tails, discussed in sections S7 and S8. All needle compositions (Table S4) are consistent with what would be expected for SAPO-34, and the coke contents are similar to our previous APT study of MTH reacted zeolite ZSM-5, with some variation between needles. ${ }^{19}$ Our group has previously studied MTH coking in both of these catalysts in detail, especially using UV-vis (micro)spectroscopy, and found that both contain occluded methylated benzenium cations, while ZSM-5 also contains extended conjugated aromatic species, which are too bulky to be occluded within the cages of SAPO-34. ${ }^{27,28}$ Also, the coke is able to penetrate further into ZSM-5 than into SAPO-34 due to the larger pores, although clear internal diffusion barriers exist, which are consistent with the range of coke contents observed by APT. ${ }^{29}$

\section{RESULTS AND DISCUSSION}

The search for heterogeneities in APT data was begun by eye to look for large segregations of elements to later quantify using isosurface analysis or cluster analysis (maximum separation method). A reconstruction of a $\mathrm{MTH}$ reacted needle (20) is shown in Figure 1 and movie S1, and a template containing needle is shown in Figure S11 and movie S2. In all needles, we were unable to observe any heterogeneities in framework elements or template elements. Isosurface analysis (details in section S8) of the distribution of ${ }^{13} \mathrm{C}$, which was visually heterogeneous, found a $7 \%{ }^{13} \mathrm{C}$ isosurface (Figure 1e and movie $\mathrm{S} 1$, bulk ${ }^{13} \mathrm{C}$ content is $3.5 \%$ ), indicating a noneven coke distribution as a result of the MTH reaction in SAPO-34, 

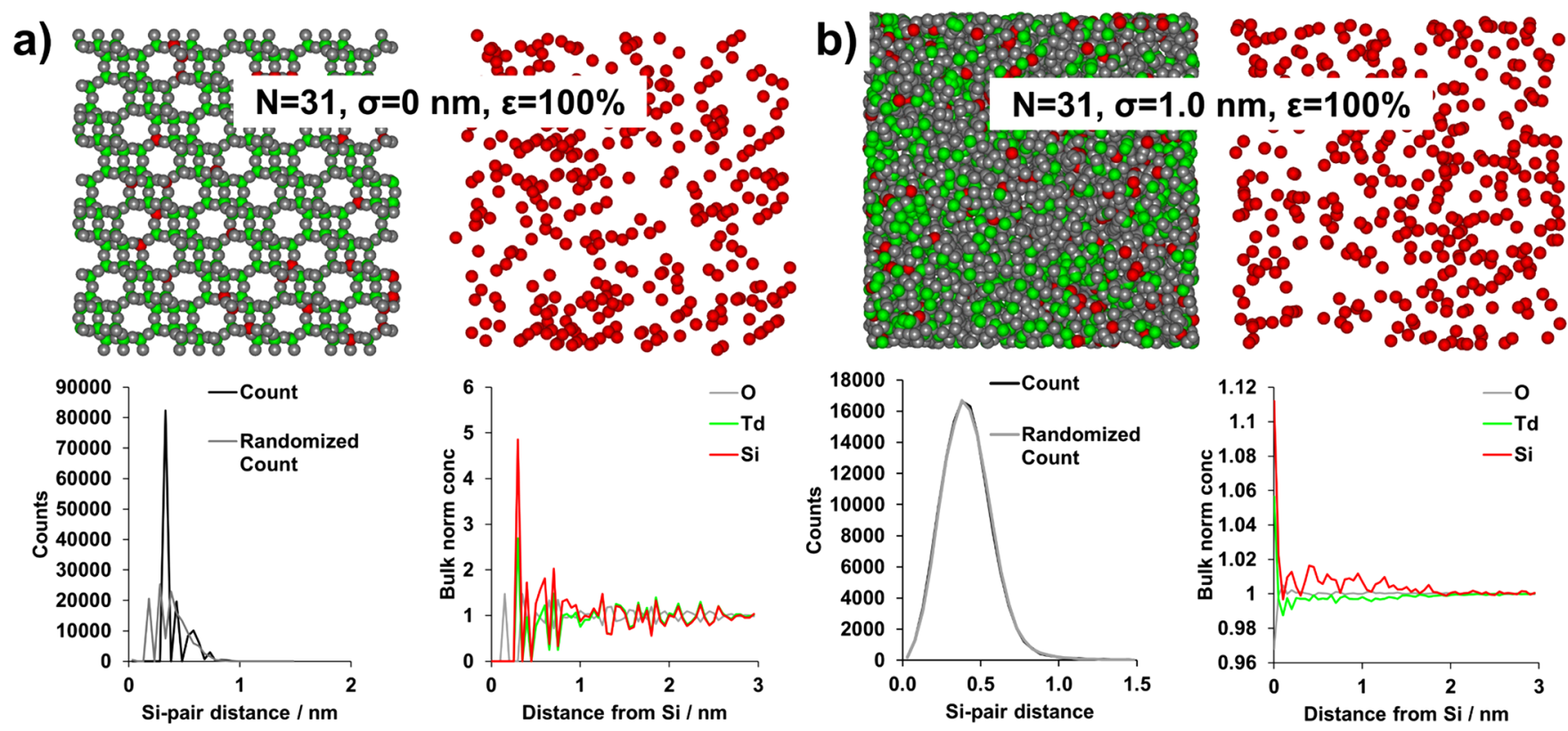

Figure 2. Selected results of atom probe simulations for the largest island sizes simulated $\left(N_{\mathrm{Si}}=31\right)$ for $100 \%$ detector efficiency $(\varepsilon)$ and two different spatial resolutions $(\sigma)$. Each panel contains a $5 \times 5 \times 5 \mathrm{~nm}^{3}$ view of all atoms that were removed from the center of the larger simulated data set, as well as a view of only the $\mathrm{Si}$ atoms, with colors as shown in the radial distribution function (RDF) graph. Also shown are the nearest neighbor distributions (NNDs) for $\mathrm{Si}$ and the RDF for $\mathrm{Si}$. Full results for all values of $N_{\mathrm{Si}}, \sigma$, and $\varepsilon$ can be found in Figures $\mathrm{S} 21$ and $\mathrm{S} 22$. (a) $N_{\mathrm{Si}}=$ $31, \sigma=0 \mathrm{~nm}$, and $\varepsilon=100 \%$. (b) $N_{\mathrm{Si}}=31, \sigma=1.0 \mathrm{~nm}$, and $\varepsilon=100 \%$. Note in (a) the view with only $\mathrm{Si}$ atoms has been slightly rotated as compared to the view with all atoms, so all $\mathrm{Si}$ atoms within the region of interest are visible. Movies of the ion distributions for the simulations are included as movie S3.

but not with the same coke depleted regions as we previously reported for ZSM-5. ${ }^{19}$ The heterogeneity in the ${ }^{13} \mathrm{C}$ distribution is also apparent from the ${ }^{13} \mathrm{C}$ nearest neighbor distribution (NND, Figure $1 \mathrm{~g}$ ) and ${ }^{13} \mathrm{C}$ radial distribution function (RDF, Figure 1h), both of which indicated a ${ }^{13} \mathrm{C}-{ }^{13} \mathrm{C}$ affinity. Therefore, a cluster analysis of the ${ }^{13} \mathrm{C}$ was performed (section S16), but identified only a few more ${ }^{13} \mathrm{C}$ clusters than would be expected in a random distribution (Figure 1e, movie $\mathrm{S} 1$, and Table S6). The $\mathrm{Si} /(\mathrm{Si}+\mathrm{Al}+\mathrm{P})$ ratio was found to be higher in the carbon clusters than in the bulk (section S16), indicating a relationship between coke deposition and Brønsted acidity. This is consistent with the ${ }^{13} \mathrm{C} \mathrm{RDF}$ as it also shows an increase in the $\mathrm{Si} /(\mathrm{Si}+\mathrm{Al}+\mathrm{P})$ ratio. However, both the ${ }^{13} \mathrm{C}$ clusters and the ${ }^{13} \mathrm{C}$ RDF show that while the $\mathrm{Si} /$ $(\mathrm{Al}+\mathrm{P}+\mathrm{Si})$ ratio increases, the $\mathrm{P} /(\mathrm{Al}+\mathrm{P}+\mathrm{Si})$ ratio increases and $\mathrm{Al} /(\mathrm{Al}+\mathrm{P}+\mathrm{Si})$ ratio decreases (Table S6 and Figure S17), and this finding is counterintuitive as $\mathrm{Si}$ should first replace $\mathrm{P}$ in the SAPO-34 framework. Therefore, we have found a preliminary indication of a relationship between Brønsted acidity and coke deposition, although additional investigations are necessary to further explore this nanoscale relationship.

The MTH reaction coking behavior in SAPO-34 and ZSM-5 is compared in Figure le and f, with two main differences: (1) ZSM-5 contains significant coke depleted regions found in two of five studied APT needles (Figure 1f), which were not found in any of the six studied SAPO-34 APT needles, although SAPO-34 does contain variations in the coke content (Figure 1e). However, overinterpretation of these differences should be cautioned due to the low volumes APT is able to sample relative to bulk materials. (2) In ZSM-5, numerous, large coke clusters could be isolated, but in SAPO-34 only a few, small clusters. These differences can be attributed to material differences: (1) The SAPO composition leads to a wider range of Brønsted acid site strengths than are found in ZSM-5.
(2) SAPO-34 is a small-pore material with cages while ZSM-5 contains larger pores of intersecting 10-membered rings, so the spatial constraints of SAPO-34 only allow smaller coke molecules, which may not be detected by APT due to spatial blurring. ${ }^{25,27}$ Overall, APT analysis of coke deposition from the MTH reaction in SAPO-34 has shown that larger coke species (clusters) form near areas of increased Brønsted acid site density, providing a catalyst design criterion to help avoid these large species that block pores and cause deactivation. Therefore, the APT findings provide an even higher resolution picture that reinforces significant nanoscale differences between ZSM-5 and SAPO-34, which is below the resolving power of many techniques.

The Si distribution was first examined using isosurface analysis, and while isosurfaces could be drawn, none were significant. As isosurfaces can always be defined around random fluctuations in the data their significance must be rigorously evaluated, especially by comparing to randomized data, the same as for cluster analysis. ${ }^{23}$ The Si NNDs do not show deviation from a random distribution (Figures $1 \mathrm{~g}$ and S12), so the Si RDFs were then examined to look for small length scale affinities between elements (Figures $1 \mathrm{~h}, \mathrm{~S} 15$, and $\mathrm{S} 16)$. In many of the Si RDFs it appears that a small $\mathrm{Si}-\mathrm{Si}$ affinity is observed, which would be consistent with the existence of $\mathrm{Si}$ islands, and it was the most pronounced in the coked materials. It is possible this is due to Si migration, which has been shown before with high temperature steaming, and could also occur during the MTH reaction as water is a byproduct. ${ }^{30}$ We combined RDF data sets within each sample to reduce counting errors (Figures $1 \mathrm{~h}$ and S16), which led to a more apparent $\mathrm{Si}-\mathrm{Si}$ affinity. Also apparent in this figure is that $\mathrm{P}$ decreases near $\mathrm{Si}$ as compared to $\mathrm{Al}$, which is expected as $\mathrm{Si}$ first replaces $\mathrm{P}$ (Figure 1), and observing it shows we obtained high spatial resolution data. It is difficult to assess if a $\mathrm{Si}-{ }^{13} \mathrm{C}$ 
affinity can be found as the heterogeneous ${ }^{13} \mathrm{C}$ distribution skews this analysis, and is further discussed in Figures S16 and S18. In the template containing crystals, $\mathrm{C}$ and $\mathrm{N}$ affinities were examined as the template molecule, morpholine, contains both $\mathrm{C}$ and N. The NNDs (Figure S13) do not show any deviation from random, but in the RDFs (Figure S19) there are clear $\mathrm{C}-\mathrm{C}, \mathrm{C}-\mathrm{N}, \mathrm{N}-\mathrm{C}$, and $\mathrm{N}-\mathrm{N}$ affinities, as well as a decrease in the content of framework elements near $\mathrm{C}$ and $\mathrm{N}$. In addition, $\mathrm{C}_{x} \mathrm{~N}_{y} \mathrm{O}_{z}$ molecules were found in the mass spectrum (Figure S10). These affinities would be expected as these elements are contained in the template, but finding them is encouraging for isolating heterogeneities.

The ability of APT to isolate $\mathrm{Si}$ islands as statistically significant features in 3-D was examined as a function of $\mathrm{Si}$ island size $\left(N_{\mathrm{Si}}\right)$, spatial resolution $(\sigma$, applied as a dislocation in 3-D space subject to a 3-D Gaussian distribution), and detector efficiency $(\varepsilon)$, using an extension of our recently reported method (section S18). ${ }^{23}$ With $\sigma=0 \mathrm{~nm}$ the complete crystallographic data are conserved, and with $\sigma=0.25 \mathrm{~nm}$ all crystallographic ordering is lost (see Figure S22). The NNDs and RDFs for the simulated data (Figures 2, S21, and S22) allow determination of the values of $N_{\mathrm{Si}}, \sigma$, and $\varepsilon$ at which indications of $\mathrm{Si}$ islands disappear. It is apparent that $\varepsilon$ has the least significant influence on the results, and only serves to shift the NND maximum to slightly larger values, as would be expected due to fewer atoms per unit volume, as well as reducing the number of counts for the NND. This observation is consistent with our experimental results comparing the LEAP 4000X HR and LEAP 5000 XS instruments, where the higher collection efficiency of the LEAP $5000 \mathrm{XS}$ leads to a shorter Si-pair distance (Figure S20), although this does not lead to a significantly increased ability to detect $\mathrm{Si}$ islands (section S17). However, it needs to be emphasized that the three simulated $\varepsilon$ 's are high, consistent with modern LEAP detector efficiencies. It is such that at low $\varepsilon$ there would be a significant impact, although the $\sigma$ and $N_{\mathrm{Si}}$ values are the most influential parameters for determining the capability to detect $\mathrm{Si}-\mathrm{Si}$ affinity, outweighing the minor influence of $\varepsilon$ in the range studied ( $\varepsilon \geq 33 \%$ ). For all $\sigma=0 \mathrm{~nm}$ data sets, both the RDFs and the NNDs show crystallographic ordering as the nearest neighbor is always $\mathrm{O}$, followed by $\mathrm{Si}$ or a different tetrahedral atom $\left(T_{\mathrm{d}}\right.$, which will be $\mathrm{Al}$ or $\left.\mathrm{P}\right)$, although ordering is not retained over long distances as any affinity will be quickly averaged over a large volume in 3-D space (randomized NNDs will also show crystallographic order as the randomization is done by element, not position). At $\sigma=0.05$ and $0.1 \mathrm{~nm}$, the $\mathrm{RDF}$ still show crystallographic ordering as $\mathrm{O}$ is the nearest neighbor. Information is lost regarding the nearest neighbor at greater values of $\sigma$, and the normalized $\mathrm{O}$ concentration becomes its bulk value at all $N_{\mathrm{Si}}$ and $\varepsilon$, and the NNDs also reflect the heterogeneous $\mathrm{Si}$ distribution. A clear $\mathrm{Si}-\mathrm{Si}$ affinity is still observed in the RDFs at all island sizes with $\sigma=0.25$ $\mathrm{nm}$, but it is more pronounced for larger islands. The NNDs no longer show a clear separation between the simulated and randomized data, illustrating that even at $\sigma=0.25 \mathrm{~nm}$ one of the key markers (the NND) no longer indicates $\mathrm{Si}-\mathrm{Si}$ affinity. At $\sigma=0.5 \mathrm{~nm}, \mathrm{Si}-\mathrm{Si}$ affinity is still present in the RDFs, although much lower in magnitude, but still increasing with $N_{\mathrm{Si}}$. The highest value of $\sigma$ simulated, $1 \mathrm{~nm}$, leads to the loss of any $\mathrm{Si}-\mathrm{Si}$ affinity in the RDFs except for the largest simulated island size, 31 atoms, although even this is nearly insignificant in magnitude (Figure 2b).
While comparing the experimental and simulated data, the potential island sizes must be considered. ssNMR shows a $\mathrm{Si}(\mathrm{OSi})_{4}$ environment as a maximum of about $50 \%$ of all $\mathrm{Si}$ species, meaning that large islands would be possible. In all of our experimental data, no significant deviation from a random distribution was found in the NNDs, so the APT spatial blurring must be greater than $0.25 \mathrm{~nm}$. The majority of the experimental RDFs show, at best, a minor $\mathrm{Si}-\mathrm{Si}$ affinity, with the combination of all coke containing materials giving the strongest indication. Therefore, we believe that the spatial resolution of APT as applied to zeolite catalysts is $0.5-1 \mathrm{~nm}$, although it may be poorer in materials with a significant organic content, such as the template containing microporous materials. This spatial resolution makes it impossible to isolate $\mathrm{Si}$ islands in 3-D space with cluster or isosurface analysis, but it is important to emphasize that we do observe a significant $\mathrm{Si}-$ Si affinity in the RDFs.

\section{CONCLUSION}

In SAPO-34, we have been able to isolate statistically significant heterogeneities at multiple scales: (1) coke clusters of a size consistent with known coke species, (2) an affinity between Brønsted acidic Si and coke, (3) affinities between template elements, (4) a Si-Si affinity, and (5) a decrease of P near $\mathrm{Si}$, consistent with the known $\mathrm{Si}$ substitution mechanism into the SAPO-34 framework. Simulations show that Si islands cannot be isolated in 3-D primarily due to instrument spatial resolution and Si cluster size within the APT needles studied, which makes it impossible to isolate small clusters with certainty. This work has broader implications toward catalysts, as well as inorganic solids and inorganic/organic hybrid materials, as it suggests that the ultimate resolution of APT with these materials is poorer than it is for the highly conductive, single-crystal metals used to determine APT's resolution specification. Further, spatial resolution has been shown to be more vital than detector efficiency (for modern instrument efficiencies) for cluster detection by APT in a reasonably high solute containing matrix, such as SAPO-34. Therefore, future APT developments should prioritize the improvement of spatial resolution to obtain the highest quality data.

\section{ASSOCIATED CONTENT}

\section{Supporting Information}

The Supporting Information is available free of charge on the ACS Publications website at DOI: 10.1021/jacs.8b04494.

SAPO-34 literature survey, SAPO-34 synthesis, powder $\mathrm{X}$-ray diffraction patterns, ${ }^{29} \mathrm{Si}$ ssNMR spectra, description of APT data analysis, needle compositions, and full APT data analysis results for all needles and simulations including RDFs and NNDs (PDF)

Movie S1 (MPG)

Movie S2 (MPG)

Movie S3 (MPG)

\section{AUTHOR INFORMATION}

\section{Corresponding Authors}

*poplawskyjd@ornl.gov

*b.m.weckhuysen@uu.nl

ORCID

Wei Guo: 0000-0002-9534-1902

Abhishek Dutta Chowdhury: 0000-0002-4121-7375 
Bert M. Weckhuysen: 0000-0001-5245-1426

\section{Present Addresses}

${ }^{\perp}$ DSM Food Specialties, DSM Biotechnology Center, R\&D Analysis, Alexander Flemminglaan 1, 2613 AX Delft, The Netherlands.

\# Department of Earth Sciences, Environmental Hydrogeology Group, Utrecht University, 3512 JE Utrecht, The Netherlands. ${ }^{\nabla}$ Department of Materials Design and Innovation, University at Buffalo, Buffalo, New York 14260, United States.

\section{Notes}

The authors declare no competing financial interest.

\section{ACKNOWLEDGMENTS}

This work is supported by the NWO Gravitation program, Netherlands Center for Multiscale Catalytic Energy Conversion (MCEC), and a European Research Council (ERC) Advanced Grant (no. 321140). The NMR studies were supported by NWO (TOP-PUNT grant to M.B., no. 718.015.001) and by uNMR-NL, the National Roadmap Large-Scale NMR Facility for The Netherlands (no. 184.032.207). The APT measurements were conducted at the Center for Nanophase Materials Sciences, which is a DOE Office of Science User Facility. J.E.S. has received funding from the European Union's Horizon 2020 research and innovation program under the Marie Sklodowska-Curie grant agreement no. 702149. Linqing Peng participated in this work at ORNL under the Oak Ridge Science Semester (ORSS) program.

\section{REFERENCES}

(1) Primo, A.; Garcia, H. Chem. Soc. Rev. 2014, 43, 7548-7561.

(2) Vermeiren, W.; Gilson, J.-P. Top. Catal. 2009, 52, 1131-1161.

(3) Corma, A. Angew. Chem., Int. Ed. 2016, 55, 6112-6113.

(4) Thomas, J. M.; Midgley, P. A. ChemCatChem 2010, 2, 783-798.

(5) Tian, P.; Wei, Y.; Ye, M.; Liu, Z. ACS Catal. 2015, 5, 19221938.

(6) Olsbye, U.; Svelle, S.; Bjørgen, M.; Beato, P.; Janssens, T. V. W.; Joensen, F.; Bordiga, S.; Lillerud, K. P. Angew. Chem., Int. Ed. 2012, $51,5810-5831$.

(7) Zhao, H.; Shi, S.; Wu, J.; Ding, Y.; Li, N. Chin. J. Catal. 2016, 37, 227-233.

(8) Sastre, G.; Lewis, D. W.; Catlow, C. R. A. J. Mol. Catal. A: Chem. 1997, 119, 349-356.

(9) Bleken, F.; Bjørgen, M.; Palumbo, L.; Bordiga, S.; Svelle, S.; Lillerud, K.-P.; Olsbye, U. Top. Catal. 2009, 52, 218-228.

(10) Hereijgers, B. P. C.; Bleken, F.; Nilsen, M. H.; Svelle, S.; Lillerud, K. P.; Bjørgen, M.; Weckhuysen, B. M.; Olsbye, U. J. Catal. 2009, 264, 77-87.

(11) Ashtekar, S.; Chilukuri, S. V. V.; Chakrabarty, D. K. J. Phys. Chem. 1994, 98, 4878-4883.

(12) Zheng, J.; Zhang, W.; Liu, Z.; Huo, Q.; Zhu, K.; Zhou, X.; Yuan, W. Microporous Mesoporous Mater. 2016, 225, 74-87.

(13) Ye, L.; Cao, F.; Ying, W.; Fang, D.; Sun, Q. J. Porous Mater. 2011, 18, 225-232.

(14) Shen, W.; Li, X.; Wei, Y.; Tian, P.; Deng, F.; Han, X.; Bao, X. Microporous Mesoporous Mater. 2012, 158, 19-25.

(15) Briend, M.; Vomscheid, R.; Peltre, M. J.; Man, P. P.; Barthomeuf, D. J. Phys. Chem. 1995, 99, 8270-8276.

(16) Pinilla-Herrero, I.; Márquez-Álvarez, C.; Sastre, E. Catal. Sci. Technol. 2017, 7, 3892-3901.

(17) Li, Z.; Martínez-Triguero, J.; Concepción, P.; Yu, J.; Corma, A. Phys. Chem. Chem. Phys. 2013, 15, 14670-14680.

(18) Dai, W.; Wu, G.; Li, L.; Guan, N.; Hunger, M. ACS Catal. 2013, 3, 588-596.
(19) Schmidt, J. E.; Poplawsky, J. D.; Mazumder, B.; Attila, Ö.; Fu, D.; de Winter, D. A. M.; Meirer, F.; Bare, S. R.; Weckhuysen, B. M. Angew. Chem., Int. Ed. 2016, 55, 11173-11177.

(20) Perea, D. E.; Arslan, I.; Liu, J.; Ristanović, Z.; Kovarik, L.; Arey, B. W.; Lercher, J. A.; Bare, S. R.; Weckhuysen, B. M. Nat. Commun. 2015, 6, 7589.

(21) Devaraj, A.; Vijayakumar, M.; Bao, J.; Guo, M. F.; Derewinski, M. A.; Xu, Z.; Gray, M. J.; Prodinger, S.; Ramasamy, K. K. Sci. Rep. 2016, 6, 37586.

(22) Gao, F.; Zheng, Y.; Kukkadapu, R. K.; Wang, Y.; Walter, E. D.; Schwenzer, B.; Szanyi, J.; Peden, C. H. F. ACS Catal. 2016, 6, 29392954.

(23) Schmidt, J. E.; Peng, L.; Poplawsky, J. D.; Weckhuysen, B. M. Angew. Chem., Int. Ed. 2018, DOI: 10.1002/anie.201712952.

(24) Kovarik, L.; Washton, N. M.; Kukkadapu, R.; Devaraj, A.; Wang, A.; Wang, Y.; Szanyi, J.; Peden, C. H. F.; Gao, F. ACS Catal. 2017, 7, 2458-2470.

(25) Schmidt, J. E.; Oord, R.; Guo, W.; Poplawsky, J. D.; Weckhuysen, B. M. Nat. Commun. 2017, 8, 1666.

(26) Vomscheid, R.; Peltre, M. J.; Barthomeup, D. J. Phys. Chem. 1994, 98, 9614-9618.

(27) Mores, D.; Stavitski, E.; Kox, M. H. F.; Kornatowski, J.; Olsbye, U.; Weckhuysen, B. M. Chem. - Eur. J. 2008, 14, 11320-11327.

(28) Qian, Q.; Ruiz-Martínez, J.; Mokhtar, M.; Asiri, A. M.; AlThabaiti, S. A.; Basahel, S. N.; van der Bij, H. E.; Kornatowski, J.; Weckhuysen, B. M. Chem. - Eur. J. 2013, 19, 11204-11215.

(29) Karwacki, L.; Kox, M. H. F.; Matthijs de Winter, D. A.; Drury, M. R.; Meeldijk, J. D.; Stavitski, E.; Schmidt, W.; Mertens, M.; Cubillas, P.; John, N.; Chan, A.; Kahn, N.; Bare, S. R.; Anderson, M.; Kornatowski, J.; Weckhuysen, B. M. Nat. Mater. 2009, 8, 959-965.

(30) Arstad, B.; Lind, A.; Cavka, J. H.; Thorshaug, K.; Akporiaye, D.; Wragg, D.; Fjellvåg, H.; Grønvold, A.; Fuglerud, T. Microporous Mesoporous Mater. 2016, 225, 421-431. 